\title{
RELATIVE REINSURANCE RETENTION LEVELS
}

\author{
DAVID C.M. DICKSON \\ University of Melbourne \\ HOWARD R. WATERS \\ Heriot-Watt University \\ Edinburgh
}

\begin{abstract}
The problem of determining optimal retention levels for a non-life portfolio consisting of a number of independent sub-portfolios was first discussed by de Finetti (1940). He considered retention levels as optimal if they minimised the variance of the insurer's profit from the portfolio subject to the constraint of a fixed level of expected profit. In this paper we consider a similar problem, changing the criterion for optimality to minimising the probability of ruin, either in discrete or continuous time. We investigate this problem through a series of case studies based on a real portfolio.
\end{abstract}

\section{KEYWORDS}

Reinsurance; optimal retention levels; finite time ruin; translated gamma process.

\section{INTRODUCTION}

This paper is a risk-theoretic discussion of the problem of determining the relative reinsurance retention levels for a non-life portfolio consisting of a number of independent sub-portfolios. We consider only simple forms of proportional and excess loss reinsurance. Our discussion will be based largely on numerical results derived from a "pseudo-real" portfolio. The characteristics and construction of this portfolio are described in detail in Section 2 below.

The classical results in this area are due to de Finetti (1940) (see also Bühlmann (1970, section 5.2)). De Finetti derived relative retention levels which have simple forms by considering the insurer's net (of reinsurance) profit from the portfolio at the end of a given time period. He then minimised the variance of this profit subject to its expected value being fixed. A summary of de Finetti's results is given in Section 3 below.

In Section 4 we discuss some alternative criteria for determining relative retention levels. These alternatives are to minimise the insurer's probability of ruin over a finite time horizon, either in continuous or in discrete time. Questions of interest to us are: 
(1) Do some or all of our probability of ruin criteria produce relative retention levels close to those given by de Finetti's approach?

(2) Are the relative retention levels produced by a probability of ruin in continuous time criterion close to those produced by a discrete time criterion?

(3) How do the relative retention levels produced by our probability of ruin criteria depend on:

(i) the insurer's expected net profit?

(ii) the time horizon for ruin?

(iii) the insurer's initial surplus?

These questions are investigated in Section 5 (proportional reinsurance) and Section 6 (excess loss reinsurance). Our conclusions are set out in Section 7.

\section{THE PORTFOLIO}

In order to investigate the problems outlined in the previous section, we have constructed a non-life insurance portfolio based on a study by Ramlau-Hansen of data supplied by a Danish insurance company. Ramlau-Hansen's work is detailed in a series of working papers (1986a, 1986b, 1986c and 1986d) and a conference paper (1983) and summarised in two papers (1988a and 1988b).

Ramlau-Hansen analysed data from the Nye Danske Lloyd insurance company covering the period 1977 to 1981 . The data related to policies on:

- single-family houses, and,

- dwellings (mainly apartment buildings, but also some office buildings).

These policies covered the buildings, but not their contents, against:

- glass damage, i.e. damage to windows and sanitary fittings,

- fire damage, and,

- windstorm damage.

Claims from these three sources will have very different characteristics:

- Glass claims: these will be relatively numerous but for rather small amounts.

- Fire claims: these will be far less frequent than glass claims but will be for far greater amounts.

- Windstorm claims: the number of windstorms will be very small but each windstorm will produce a large number of individual claims.

In terms of claims experience, we would expect glass claims to be relatively stable, fire claims to be less stable and windstorm claims to be even less stable over time.

Our portfolio is based on Ramlau-Hansen's "Standard Portfolio" (1986d, section 4.3). It consists of three sub-portfolios covering glass, fire and windstorm claims, each of which can be reinsured separately. However, within each subportfolio, singlefamily houses and dwellings cannot be reinsured separately. The total annual expected claim amount, before reinsurance, is $500 \times 10^{6}$ of which $25 \%\left(125 \times 10^{6}\right)$ is expected to come from glass claims, $70 \%\left(350 \times 10^{6}\right)$ from fire claims and the remaining $5 \%$ $\left(25 \times 10^{6}\right)$ from windstorm claims. (Ramlau-Hansen's monetary unit was Danish Kroner at 1981 values. For our purposes only relative monetary values are important, not absolute values.) 
Ramlau-Hansen modelled in some detail the annual claim numbers and amounts distributions for each sub-portfolio. We have adopted Ramlau-Hansen's models for our portfolio with some very minor simplifications. Our models are as follows:

Glass claims: Since glass claim amounts are almost always relatively small, we have assumed that this sub-portfolio would not be reinsured under an excess loss treaty, but would be reinsured under a proportional reinsurance treaty. (This agrees with Ramlau-Hansen's study (1988b, section 3.2).) For this reason we need to specify a model for the aggregate annual glass claims but not for claim numbers and claim amounts separately. We have assumed that the aggregate annual glass claims have a normal distribution. This is a slight simplification of Ramlau-Hansen's model but his analysis (1986a, Table 12) does show that the skewness of aggregate annual glass claims is very small. The expected aggregate annual glass claims are $125 \times 10^{6}$, as explained above, and we have taken the standard deviation to be $4.3 \times 10^{6}$. The standard deviation has been inferred from the information given by Ramlau-Hansen (1986a, Table 14).

Fire claims: The annual fire claim rate for dwellings is about 0.0885 . (See RamlauHansen (1986b, Tables 1 and 2).) The annual fire claim rate for single-family houses is 0.0127. (See Ramlau-Hansen (1983, Tables 1 and 7).) In 1981, the numbers of dwellings and single-family houses in Ramlau-Hansen's data were 12,318 and 83,699, respectively. These figures indicate that the expected number of claims each year is approximately the same for dwellings and single-family houses. Ramlau-Hansen (1988a, section 2.1) assumes claim numbers have a Poisson distribution. We have assumed the Poisson parameter for dwellings and for single-family houses is 7,893.9. (This value, when combined with the claim amount distributions specified below, gives a mean aggregate annual fire claim amount of $350 \times 10^{6}$, as required.)

We use different claim amount distributions for dwellings and for single-family houses. In each case, the distribution is loggamma, truncated at an expected maximum loss (EML), with a density function of the form:

$$
f(x ; \alpha, \gamma)=\frac{\alpha^{\gamma}}{\Gamma(\gamma)} \frac{1}{x_{0}}\left(\log \left(x / x_{0}\right)\right)^{\gamma-1}\left(x / x_{0}\right)^{-(\alpha+1)} \quad \text { for } x_{0}<x<E M L
$$

where in each case the lower limit $x_{0}$ is 100 . The other parameters and the resulting moments are:

\begin{tabular}{lcc} 
& Dwellings & Single-family houses \\
\hline$E M L$ & $35 \times 10^{6}$ & 402,500 \\
$\alpha$ & 1.4177 & 1.1220 \\
$\gamma$ & 5.1003 & 3.2477 \\
Mean & 33,611 & 10,727 \\
St. Dev. & 490,721 & 42,560 \\
Skewness & 51.64 & 7.338
\end{tabular}

Ramlau-Hansen (1988a, section 2.2 and 1983, section 3) uses parameter values which depend on the floor area of the dwelling or house. We have selected a "typical" distri- 
bution for each type of property. Let $F(x ; \alpha, \gamma)$ denote the distribution function corresponding to the density function $f(x ; \alpha, \gamma)$. Then the aggregate annual fire claims have a compound Poisson distribution with Poisson parameter 15,787.8 and individual claim amount distribution $F(x)$, where:

$F(x)=0$ for $x<100$

$F(x)=(F(x ; 1.4177,5.1003)+F(x ; 1.1220,3.2477)) / 2$ for $100 \leq x<402,500$

$F(x)=(1+F(x ; 1.4177,5.1003)) / 2$ for $402,500 \leq x<35 \times 10^{6}$

$F(x)=1$ for $x \geq 35 \times 10^{6}$

For our model, aggregate annual fire claims have the following moments:

$\begin{array}{ll}\text { Mean } & 350 \times 10^{6} \\ \text { St. Dev. } & 43.875 \times 10^{6} \\ \text { Skewness } & 0.571\end{array}$

Windstorm claims: Ramlau-Hansen (1988a) developed a complicated model for windstorms. He modelled the number of storms per annum, the number of claims from each storm and the amount of the individual claims. For the purposes of proportional reinsurance we need model only the aggregate annual windstorm claims. When we consider excess loss reinsurance, we shall assume the insurer protects the windstorm (sub-)portfolio with a catastrophe excess loss treaty whereby the reinsurer reimburses the insurer for the amount by which the total claim amount caused by a storm exceeds a given retention. See Ramlau-Hansen (1986c, p. 42). This means that we need model only the annual number of windstorms and the total claim amount from each windstorm.

The number of windstorms per annum (in Denmark) in Ramlau-Hansen's model has a Poisson distribution with mean 4.36 and the expected cost of a single windstorm is $9.3 \times 10^{6}$. Since we require the expected aggregate annual cost of windstorms to be $25 \times 10^{6}$, we need to scale down either the expected number of windstorms or the expected cost of a single windstorm. We decided to do the latter, which is equivalent to an insurer (in Denmark) having fewer windstorm policies than in Ramlau-Hansen's portfolio.

Our model for windstorm claims is as follows:

The number of storms per annum has a Poisson distribution with mean 4.36.

The total claim amount from a single windstorm has the following moments:

$\begin{array}{ll}\text { Mean } & 5.734 \times 10^{6} \\ \text { St. Dev. } & 13.14 \times 10^{6} \\ \text { Skewness } & 2.649\end{array}$

We have assumed that the total claim amount from a single windstorm has a translated gamma distribution with the above moments, i.e. has the distribution of $\kappa+Y$, where $Y$ has a $\Gamma(\alpha, \beta)$ distribution. The parameters of this distribution are:

$$
\begin{aligned}
& \alpha=0.5700 \\
& \beta=5.746 \times 10^{-8} \\
& \kappa=-4.187 \times 10^{6}
\end{aligned}
$$


This model gives the following moments for the aggregate annual claims from windstorms:

$$
\begin{array}{ll}
\text { Mean } & 25 \times 10^{6} \\
\text { St. Dev. } & 29.936 \times 10^{6} \\
\text { Skewness } & 1.49
\end{array}
$$

Following Ramlau-Hansen, we assume that all random variables in our model are independent unless specified otherwise, so that, for example, aggregate claims from the three sub-portfolios are independent and aggregate claims in separate years are independent. In addition, we assume that the distributions do not change from year to year. It would not be difficult to relax this assumption, for example by incorporating inflation and business growth, but this would complicate the presentation without adding significantly to the study.

For the remainder of the paper we will work in units of one million, so that the expected aggregate annual claim amount from the portfolio is 500 .

\section{A REVIEW OF DE FINETTI'S RESULTS}

This section contains a brief summary of the essential points of de Finetti's results. More details, and proofs, can be found in de Finetti (1940) (see also Bühlmann (1970)). The basic idea underlying these results is as follows. An insurer has a portfolio on $n$ independent risks and wishes to effect the same type of reinsurance for each risk. The insurer's profit level from these risks clearly depends on the level of reinsurance. The insurer fixes a level for its expected profit from the portfolio over a given time period, say one year, and chooses retention levels to minimise the variance of the profit from the portfolio over this period. De Finetti's results state how retention levels for proportional and excess loss reinsurance should be calculated under this criterion, which we shall refer to as the minimum variance criterion.

Consider first proportional reinsurance. For a portfolio of $n$ independent risks, let $S_{i}$ denote aggregate claims from the $i$ th risk in a fixed time period for $i=1,2, \ldots, n$, and let $P_{i}$ denote the premium received by the insurer to cover this risk. The insurer effects proportional reinsurance for each risk with proportion $a_{i}$ retained for the $i$ th risk, paying a reinsurance premium of $\left(1+\theta_{i}\right)\left(1-a_{i}\right) E\left(S_{i}\right)$ for this reinsurance cover. Thus, the reinsurance premium is calculated by the expected value principle with a loading $\theta_{i}$ for the $i$ th risk. The insurer's profit over the period is

$$
Z(\underline{a})=\sum_{i=1}^{n}\left(P_{i}-\left(1+\theta_{i}\right)\left(1-a_{i}\right) E\left(S_{i}\right)-a_{i} S_{i}\right)
$$

Subject to the constraint $E[Z(\underline{a})]=k$, where $k$ is a constant, $V[Z(\underline{a})]$ is minimised by

$$
a_{i}=\frac{c \theta_{i} E\left(S_{i}\right)}{V\left(S_{i}\right)} \text { for } i=1,2, \ldots, n
$$

where $c$ is a constant which is determined by the condition $E[Z(\underline{a})]=k$. If this procedure produces a value of $a_{i}>1$, the solution is to set that value of $a_{i}$ equal to 1 , with the remaining retentions being of the above form. 
In the case of excess loss reinsurance, let $S_{i}$ and $P_{i}$ have the same meaning as above. We assume that each $S_{i}$ has a compound Poisson distribution. The insurer effects excess loss reinsurance with retention level $M_{i}$ for the $i$ th risk and pays a reinsurance premium of $\left(1+\theta_{i}\right) E\left(S_{i}-S_{i}\right)$ where $S_{i}^{l}$ denotes the insurer's aggregate retained claim amount from the $i$ th risk. The insurer's profit over the period is

$$
Z(\underline{M})=\sum_{i=1}^{n}\left(P_{i}-\left(1+\theta_{i}\right) E\left(S_{i}-S_{i}^{l}\right)-S_{i}^{l}\right)
$$

Subject to the constraint $E[Z(\underline{M})]=k$, where $k$ is a constant, $V[Z(\underline{M})]$ is minimised by

$$
M_{i}=c \theta_{i} \quad \text { for } i=1,2, \ldots, n
$$

where $c$ is a constant which is determined by the condition $E[Z(\underline{M})]=k$.

Tables 1 and 2 show optimal retention levels for the portfolio described in Section 2 for proportional and excess loss reinsurance respectively. In the case of proportional reinsurance, the loadings in the reinsurance premiums are $10 \%$ (glass), $40 \%$ (fire) and $80 \%$ (windstorm), while for excess loss reinsurance they are $40 \%$ (fire) and $80 \%$ (windstorm). The tables also show the mean and variance of the insurer's retained aggregate claims. We can see in each case that these quantities increase as the expected net profit increases. We note that for each level of expected net profit, the values of mean retained aggregate claim amounts under each type of reinsurance are similar. However, for a given level of expected net profit, the variance of the retained aggregate claim amount is considerably smaller under excess loss reinsurance. For example, when the expected net profit is 90 , a reduction of just 10 from its maximum value, the variance of the insurer's retained aggregate claim amount can be reduced by $44 \%$ using excess loss reinsurance, compared to a reduction of only $24 \%$ using proportional reinsurance.

\section{TABLE 1}

OPTIMAL RETENTIONS - PROPORTIONAL REINSURANCE

\begin{tabular}{cccccc}
\hline $\begin{array}{c}\text { Expected } \\
\text { Net Profit }\end{array}$ & $\begin{array}{c}\text { Glass } \\
\text { Retention }\end{array}$ & $\begin{array}{c}\text { Fire } \\
\text { Retention }\end{array}$ & $\begin{array}{c}\text { Windstorm } \\
\text { Retention }\end{array}$ & Mean & Variance \\
\hline 50 & 1 & 0.753 & 0.231 & 394 & 1,157 \\
60 & 1 & 0.821 & 0.252 & 419 & 1,373 \\
70 & 1 & 0.890 & 0.273 & 443 & 1,609 \\
80 & 1 & 0.958 & 0.294 & 468 & 1,863 \\
90 & 1 & 1 & 0.5 & 488 & 2,168 \\
100 & 1 & 1 & 1 & 500 & 2,840 \\
\hline
\end{tabular}

Note that in the case of proportional reinsurance, there is in fact no reinsurance for the glass sub-portfolio, nor for the fire sub-portfolio as the expected net profit increases. In all other cases in Table 1, the retentions for the fire and windstorm portfolios are in the same proportion. In Table 2, the retention levels for windstorm claims are twice those for fire claims since the reinsurance premium loading factors are in the ratio $2: 1$. 
TABLE 2

OPTIMAL RETENTIONS - EXCESS LOSS REINSURANCE

\begin{tabular}{ccccc}
\hline $\begin{array}{c}\text { Expected } \\
\text { Net Profit }\end{array}$ & $\begin{array}{c}\text { Fire } \\
\text { Retention }\end{array}$ & $\begin{array}{c}\text { Windstorm } \\
\text { Retention }\end{array}$ & Mean & Variance \\
\hline 50 & 2.08 & 4.15 & 397 & 213 \\
60 & 3.55 & 7.09 & 418 & 351 \\
70 & 5.86 & 11.72 & 438 & 582 \\
80 & 9.66 & 19.32 & 458 & 961 \\
90 & 16.88 & 33.77 & 478 & 1,602 \\
100 & $\infty$ & $\infty$ & 500 & 2,840 \\
\hline
\end{tabular}

Thus, de Finetti's results provide simple formulae from which optimal retention levels can be calculated. In the case of proportional reinsurance, the optimal retention levels depend on the first two moments of aggregate claims from each sub-portfolio. This is perhaps not surprising since the problem is specified in terms of the first two moments of profit from the $n$ sub-portfolios considered together. In the case of excess loss reinsurance, the optimal retention level for each sub-portfolio depends only on the reinsurer's loading for that sub-portfolio. An interesting feature of this result is that the distribution of individual claims for a sub-portfolio has no bearing whatsoever on the retention level.

The results are independent of the insurer's premium income (before reinsurance) and of the amount of the insurer's surplus. Intuitively we would expect these factors to play a part. We also note that these results hold for a single period analysis. If we assume that claims in successive time periods are independent, then a change in the time period considered does not alter the optimal retention levels.

Finally, we note that if the optimality criterion is altered from minimising $V[Z(\underline{b})]$ subject to the constraint $E[Z(\underline{b})]=k$ (where $\underline{b}$ denotes the vector of retention levels) to minimising $V[Z(\underline{b})]$ subject to the constraint $E[Z(\underline{b})] \geq k$ then it is not difficult to prove that the solution to the problem is unchanged. In our case studies in Sections 5 and 6, where we apply different criteria for optimality, we will see that a change in the constraint from $E[Z(\underline{b})]=k$ to $E[Z(\underline{b})] \geq k$ can make a considerable difference.

\section{AN ALTERNATIVE CRITERION FOR OPTIMALITY}

In this section we consider an alternative criterion for optimality. We will consider a vector of retention levels to be optimal if those retentions minimise the insurer's probability of ruin (net of reinsurance) subject to the constraint that the insurer's expected profit per unit time is greater than or equal to some constant. Thus we have not only changed the objective function from variance of profit to probability of ruin, but we have also altered the constraint. It will be clear in the examples in the next sections why it is sensible to do this. In our examples we will consider finite time ruin, both in discrete and in continuous time.

Since the probability of ruin depends on all the characteristics of the surplus process, we might expect this new criterion to produce different optimal retention levels 
to those produced by the minimum variance criterion. However, the following examples suggest that this new criterion may not produce very different results.

Example 1: It is well-known that if the adjustment coefficient, denoted $R$, for a risk exists, it can be approximated as

$$
R \approx \frac{2 \times \text { Expected Profit }}{\text { Variance of Profit }}
$$

Let us treat profit in this approximation as being the net of reinsurance profit from a portfolio of risks over a fixed time period. A natural (and approximate) way of obtaining retention levels to minimise the insurer's probability of ultimate ruin would be to find retention levels that maximise this approximation to $R$. When we apply the constraint that the expected profit is constant, maximising $R$ is equivalent to minimising the variance of profit, i.e. minimising the variance of net retained claims.

Example 2: Suppose that an insurer has a portfolio of $n$ risks and receives a total premium of $P$ per annum to cover these risks. Suppose further that the insurer effects some form of reinsurance for each of these risks, defined by a vector $\underline{b}$ of retention levels. Let $\Pi(\underline{b})$ denote the total premium paid by the insurer for this reinsurance, and let $S_{n}(\underline{b})$ denote the aggregate claims, net of reinsurance, paid by the insurer up to time $n$. Finally, let $U$ denote the insurer's initial surplus.

We assume that the insurer's expected net profit per unit time, $P-\Pi(\underline{b})-\left[S_{1}(\underline{b})\right]$, is positive. Assuming that $S_{n}(\underline{b})$ has a normal distribution, and that aggregate claims are independent and identically distributed from year to year, the insurer's probability of ruin at the end of $n$ years is

$$
1-\Phi\left(\frac{n P-n \Pi(\underline{b})-n E\left(S_{1}(\underline{b})\right)+U}{\left[n V\left(S_{1}(\underline{b})\right)\right]^{1 / 2}}\right)
$$

where $\Phi$ denotes the standard normal distribution function. Minimising this probability of ruin (as a function of $\underline{b}$ ) subject to the insurer's expected net profit per unit time being fixed is equivalent to minimising the variance of the insurer's net profit per unit time subject to the same constraint.

Example 3: Now let us extend the previous example by assuming in addition that the insurer's aggregate gain process $\left\{G_{t}(\underline{b})\right\}_{t \geq 0}$ is a Brownian motion with (positive) drift. Let $\Psi(U, T \mid \underline{b})$ denote the probability of ruin in continuous time before time $T$, which may be finite or infinite. Let $\underline{b}_{1}$ and $\underline{b}_{2}$ be two reinsurance retention vectors which result in the same expected net profit for the insurer, say $\mu$ per unit time, but different variances. Then using a coupling argument, i.e. regarding $G_{t}\left(\underline{b}_{1}\right)$ as equivalent to

$$
\mu t+\left(G_{t}\left(\underline{b}_{2}\right)-\mu t\right)\left(V\left[G_{t}\left(\underline{b}_{1}\right)\right] / V\left[G_{t}\left(\underline{b}^{2}\right)\right]\right)^{1 / 2}
$$

it is easy to see that $\Psi\left(U, T \mid \underline{b}_{1}\right)>\Psi\left(U, T \mid \underline{b}_{2}\right)$ is equivalent to $V\left[G_{1}\left(\underline{b}_{1}\right)\right]>V\left[G_{t}\left(\underline{b}_{2}\right)\right]$. Hence, minimising the probability of ruin in continuous and finite or infinite time 
subject to the insurer's expected net profit per unit time being fixed is equivalent to minimising the variance of the insurer's net profit subject to the same constraint.

Each of these last two examples relies on being prepared to approximate the insurer's net surplus process by a process determined by just its mean and variance (see, for example, Grandell (1977)). They also apply the constraint that the expected net profit equals some constant, rather than is greater than or equal to that constant. Nevertheless, they suggest that a change in the optimality criterion from minimising variance to minimising a ruin probability may not result in very different retention levels. We shall see in Sections 5 and 6 that this can be the case, although we shall also see that the change in optimality criterion can lead to very different results.

Since our new optimality criterion is to minimise a probability of ruin, we need to be able to calculate ruin probabilities. Our approach to this problem will not be to attempt to calculate exact ruin probabilities. Rather, we will use an approximation. We will approximate the retained aggregate claims process by a translated gamma process. There are two reasons for using this approximation. First, formulae exist from which ruin probabilities can be calculated. Second, recent evidence shows that this approach provides very good approximations to ruin probabilities, particularly in problems involving reinsurance. See Dickson and Waters (1993 and 1996).

We conclude this section by describing how we calculated ruin probabilities. Consider first the discrete time ruin problem. We require probabilities of the form

$$
\Psi_{1}(u, t)=\operatorname{Pr}\left(u+P n-X_{n}<0 \quad \text { for some } n, n=1,2, \ldots, t\right)
$$

where $P$ represents the insurer's premium income, net of reinsurance, per unit time, and $X_{n}$ denotes aggregate claims up to time $n$, again net of reinsurance. We approximated $X_{n}$ by $Y_{n}+k n$ where $Y_{n}$ has a gamma distribution with parameters $n \alpha$ and $\beta$ and calculated probabilities from

$$
\Psi_{1}^{*}(u, t)=\operatorname{Pr}\left(u+P^{*} n-Y_{n}<0 \quad \text { for some } n, n=1,2, \ldots, t\right)
$$

where $P^{*}=P-k$. The parameters $\alpha, \beta$ and $k$ are found by matching the first three moments of $X_{n}$ and $Y_{n}+k n$. Let $G(x)$ and $g(x)$ respectively denote the distribution function and density function of a gamma distribution with parameters $\alpha$ and $\beta$, so that the mean of the distribution is $\alpha / \beta$. Then

$$
\Psi_{1}^{*}(u, 1)=1-G\left(u+P^{*}\right)
$$

and for $t=1,2,3, \ldots$

$$
\Psi_{1}^{*}(u, t+1)=\Psi_{1}^{*}(u, t)+\int_{0}^{u+P^{*}} \Psi_{1}^{*}(x, t) g\left(u+P^{*}-x\right) d x
$$

Values of $\Psi_{1}^{*}(u, 1)$ were calculated directly from computer routines which compute the gamma distribution function. Values of $\Psi_{1}^{*}(u, t)$ for $t>1$ were calculated by numerical integration. For each value of $u$ required we performed numerical integration on the interval $\left(0,\left[u+P^{*}\right]\right)$, where $\left[u+P^{*}\right]$ denotes the greatest integer less than or equal to $u+P^{*}$, by applying the repeated trapezoidal rule on unit steps. The integral over the range $\left(\left[u+P^{*}\right], u+P^{*}\right)$ was calculated by the trapezoidal rule. Thus, except for the integral over the final part of the range, $\Psi_{1}^{*}(x, t)$ values were required only for 
integer values of $x$. For the integral over $\left(\left[u+P^{*}\right], u+P^{*}\right)$ values of $\Psi_{1}^{*}(x, t)$ were required for non-integer $x$. These were obtained by linear interpolation. For our numerical examples, a unit step size was deemed to be sufficiently large in view of the parameter values in our examples. In particular, the value of $P^{*}$ was typically between 300 and 500 . form

In the case of continuous time ruin probabilities, we require probabilities of the

$$
\Psi(u, t)=\operatorname{Pr}(u+P \tau-S(\tau)<0 \text { for some } \tau, 0<\tau \leq t)
$$

where $P$ is as above and $\{S(t)\}_{t \geq 0}$ denotes the aggregate claims process, net of reinsurance. We approximate the process $\{S(t)\}_{t \geq 0}$ by the translated gamma process $\left\{S_{G}(t)+\right.$ $k t\}_{t \geq 0}$ where $\left\{S_{G}(t)\right\}_{t \geq 0}$ is a gamma process with parameters $\alpha$ and $\beta$. The parameters $\alpha, \beta$ and $k$ are found by matching the first three moments of the two processes. Ruin probabilities for the translated gamma process were calculated by the method described by Dickson and Waters (1993).

\section{PROPORTIONAL REINSURANCE}

In this section we consider the problem of choosing proportional reinsurance retention levels for each of the three sub-portfolios, glass, fire and windstorm, of the portfolio described in Section 2. We will discuss two case studies which reveal rather different features.

Case Study 1: We have set the insurer's premium income (before reinsurance) to be 600 per unit time, i.e. $120 \%$ of the expected aggregate claims. The insurer's initial surplus has been set at 20 . The initial surplus was chosen so that the one-year discrete time ruin probability is about $1 \%$ when the vector of retentions $\underline{a}$ is given by the solution under the minimum variance criterion with an expected net profit of 50 . The reinsurer's premium loading factors are $\underline{\theta}=(0.044,0.1605,1.533)$. These loading factors are in proportion to the standard deviation of aggregate claims per unit time for the three sub-portfolios and are such that, if the insurer reinsured the whole of each subportfolio, the reinsurance premium would be 600 .

Table 3A shows for the time horizons $t=1,2,5,10$ and 20 , the probability of ruin in continuous time and in discrete time assuming the insurer does not effect any reinsurance. In this case the insurer's expected net profit per unit time is 100 , as shown in the final column of Table $3 \mathrm{~A}$. 
TABLE 3A

CASE STUdY 1 - NO REINSURANCE

\begin{tabular}{ccccc}
\hline $\boldsymbol{t}$ & $\underline{a}$ & $\begin{array}{c}\text { Prob'y of ruin } \\
\text { (continuous) }\end{array}$ & $\begin{array}{c}\text { Prob'y of ruin } \\
\text { (discrete) }\end{array}$ & $\begin{array}{c}\text { Expected } \\
\text { net profit }\end{array}$ \\
\hline 1 & $(1,1,1)$ & 0.2413 & 0.0237 & 100 \\
2 & $(1,1,1)$ & 0.2484 & 0.0262 & 100 \\
5 & $(1,1,1)$ & 0.2494 & 0.0267 & 100 \\
10 & $(1,1,1)$ & 0.2495 & 0.0267 & 100 \\
20 & $(1,1,1)$ & 0.2495 & 0.0267 & 100 \\
\hline
\end{tabular}

The proportional reinsurance retention levels which minimise the variance of the insurer's net (of reinsurance) aggregate claims subject to the constraint that the insurer's expected net profit per unit time should be 50 are $\underline{a}=(1,0.396,0.581)$. Table 3B shows the insurer's probabilities of ruin with these retention levels.

TABLE 3B

CASE STUdy 1 - MINIMUM VARIANCE

\begin{tabular}{ccccc}
\hline $\boldsymbol{t}$ & $\boldsymbol{a}$ & $\begin{array}{c}\text { Prob'y of ruin } \\
\text { (continuous) }\end{array}$ & $\begin{array}{c}\text { Prob'y of ruin } \\
\text { (discrete) }\end{array}$ & $\begin{array}{c}\text { Expected } \\
\text { net profit }\end{array}$ \\
\hline 1 & $(1,0.396,0.581)$ & 0.0898 & 0.0103 & 50 \\
2 & $(1,0.396,0.581)$ & 0.0948 & 0.0115 & 50 \\
5 & $(1,0.396,0.581)$ & 0.0955 & 0.0117 & 50 \\
10 & $(1,0.396,0.581)$ & 0.0955 & 0.0117 & 50 \\
20 & $(1,0.396,0.581)$ & 0.0955 & 0.0117 & 50 \\
\hline
\end{tabular}

Table $3 \mathrm{C}$ shows for each time horizon, the retention levels which minimise the insurer's probability of ruin in continuous time subject to the insurer's expected net profit being at least 50 , the corresponding minimum probability of ruin, the probability of ruin in discrete time for these retention levels and finally the insurer's expected net profit. In this case, the optimal retention levels are such that the insurer's expected net profit is equal to 50 for each of the five time horizons.

TABLE 3C

CASE StUdy 1 - MiNIMUM PROBABILITY OF RUIN IN CONTINUOUS TIME

\begin{tabular}{ccccc}
\hline $\boldsymbol{t}$ & $\underline{\boldsymbol{a}}$ & $\begin{array}{c}\text { Prob'y of ruin } \\
\text { (continuous) }\end{array}$ & $\begin{array}{c}\text { Prob'y of ruin } \\
\text { (discrete) }\end{array}$ & $\begin{array}{c}\text { Expected } \\
\text { net profit }\end{array}$ \\
\hline 1 & $(1,0.438,0.519)$ & 0.0882 & 0.0095 & 50 \\
2 & $(1,0.438,0.519)$ & 0.0929 & 0.0106 & 50 \\
5 & $(1,0.439,0.518)$ & 0.0935 & 0.0108 & 50 \\
10 & $(1,0.439,0.518)$ & 0.0935 & 0.0108 & 50 \\
20 & $(1,0.439,0.518)$ & 0.0935 & 0.0108 & 50 \\
\hline
\end{tabular}

Table $3 \mathrm{D}$ is similar to Table $3 \mathrm{C}$ except that for each time horizon, the retention levels are those which minimise the insurer's probability of ruin in discrete time subject to the insurer's expected net profit being at least 50 . 
TABLE 3D

CASE STUdY 1 - MINIMUM PROBABILITY OF RUIN IN DISCRETE TIME

\begin{tabular}{ccccc}
\hline \hline $\boldsymbol{t}$ & $\underline{\boldsymbol{a}}$ & $\begin{array}{c}\text { Prob'y of ruin } \\
\text { (continuous) }\end{array}$ & $\begin{array}{c}\text { Prob'y of ruin } \\
\text { (discrete) }\end{array}$ & $\begin{array}{c}\text { Expected } \\
\text { net profit }\end{array}$ \\
\hline 1 & $(1,0.456,0.493)$ & 0.0885 & 0.0094 & 50 \\
2 & $(1,0.456,0.493)$ & 0.0933 & 0.0105 & 50 \\
5 & $(1,0.456,0.493)$ & 0.0939 & 0.0107 & 50 \\
10 & $(1,0.456,0.493)$ & 0.0939 & 0.0107 & 50 \\
20 & $(1,0.456,0.493)$ & 0.0939 & 0.0107 & 50 \\
\hline \hline
\end{tabular}

Case Study 2: We have again set the insurer's premium income to be 600 but have increased the initial surplus to 35 . This initial surplus gives a one-year discrete time probability of ruin of about $1 \%$ when there is no reinsurance. We have set the reinsurance premium loading factors as $\underline{\theta}=(0.1,0.4,0.8)$. These are somewhat arbitrary choices but are designed to reflect the relative risk for the three sub-portfolios. With these loadings, the premium for reinsuring the whole portfolio is greater than 600 . Adopting the same constraints as for Case Study 1, the retention levels which minimise the variance of the insurer's net claims are $(1,0.753,0.231)$.

Tables 4A, 4B, 4C and 4D give the information relating to Case Study 2 which corresponds to the information relating to Case Study 1 in Tables 3A, 3B, 3C and 3D.

TABLE 4A

CASE Study 2 - NO Reinsurance

\begin{tabular}{ccccc}
\hline $\boldsymbol{t}$ & $\underline{\boldsymbol{a}}$ & $\begin{array}{c}\text { Prob'y of ruin } \\
\text { (continuous) }\end{array}$ & $\begin{array}{c}\text { Prob'y of ruin } \\
\text { (discrete) }\end{array}$ & $\begin{array}{c}\text { Expected } \\
\text { net profit }\end{array}$ \\
\hline 1 & $(1,1,1)$ & 0.1282 & 0.0146 & 100 \\
2 & $(1,1,1)$ & 0.1347 & 0.0164 & 100 \\
5 & $(1,1,1)$ & 0.1357 & 0.0167 & 100 \\
10 & $(1,1,1)$ & 0.1357 & 0.0167 & 100 \\
20 & $(1,1,1)$ & 0.1357 & 0.0167 & 100 \\
\hline
\end{tabular}

TABLE 4B

Case Study 2 - Minimum Variance

\begin{tabular}{ccccc}
\hline \hline $\boldsymbol{t}$ & $\underline{\boldsymbol{a}}$ & $\begin{array}{c}\text { Prob'y of ruin } \\
\text { (continuous) }\end{array}$ & $\begin{array}{c}\text { Prob'y of ruin } \\
\text { (discrete) }\end{array}$ & $\begin{array}{c}\text { Expected } \\
\text { net profit }\end{array}$ \\
\hline 1 & $(1,0.753,0.231)$ & 0.0746 & 0.0147 & 50 \\
2 & $(1,0.753,0.231)$ & 0.0861 & 0.0185 & 50 \\
5 & $(1,0.753,0.231)$ & 0.0894 & 0.0199 & 50 \\
10 & $(1,0.753,0.231)$ & 0.0895 & 0.0199 & 50 \\
20 & $(1,0.753,0.231)$ & 0.0895 & 0.0199 & 50 \\
\hline
\end{tabular}


TABLE 4C

CASE STUDY 2 - MINIMUM PROBABILITY OF RUIN IN CONTINUOUS TIME

\begin{tabular}{ccccc}
\hline $\boldsymbol{t}$ & $\underline{\boldsymbol{a}}$ & $\begin{array}{c}\text { Prob'y of ruin } \\
\text { (continuous) }\end{array}$ & $\begin{array}{c}\text { Prob'y of ruin } \\
\text { (discrete) }\end{array}$ & $\begin{array}{c}\text { Expected } \\
\text { net profit }\end{array}$ \\
\hline 1 & $(1,0.749,0.257)$ & 0.0745 & 0.0147 & 50 \\
2 & $(1,0.749,0.257)$ & 0.0860 & 0.0184 & 50 \\
5 & $(1,0.749,0.257)$ & 0.0893 & 0.0198 & 50 \\
10 & $(1,0.749,0.257)$ & 0.0894 & 0.0199 & 50 \\
20 & $(1,0.749,0.257)$ & 0.0894 & 0.0199 & 50 \\
\hline
\end{tabular}

TABLE 4D

CASE STUDY 2 - MINIMUM PROBABILITY OF RUIN IN DISCRETE TIME

\begin{tabular}{ccccc}
\hline $\boldsymbol{t}$ & $\underline{\boldsymbol{a}}$ & $\begin{array}{c}\text { Prob'y of ruin } \\
\text { (continuous) }\end{array}$ & $\begin{array}{c}\text { Prob'y of ruin } \\
\text { (discrete) }\end{array}$ & $\begin{array}{c}\text { Expected } \\
\text { net profit }\end{array}$ \\
\hline 1 & $(1,1,0.42)$ & 0.0957 & 0.0103 & 88.4 \\
2 & $(1,1,0.43)$ & 0.1011 & 0.0115 & 88.6 \\
5 & $(1,1,0.43)$ & 0.1018 & 0.0118 & 88.6 \\
10 & $(1,1,0.43)$ & 0.1018 & 0.0118 & 88.6 \\
20 & $(1,1,0.43)$ & 0.1018 & 0.0118 & 88.6 \\
\hline
\end{tabular}

\section{Comparison of Tables 3A-D and 4A-D:}

(a) Comparing the ruin probabilities in Table $3 \mathrm{~A}$ (no reinsurance) with those in Tables 3B-D, and also those in Table 4A with those in Tables 4B-D, it is apparent that proportional reinsurance can reduce the probability of ruin considerably, although in many cases $50 \%$ of the maximum expected profit has been sacrificed to achieve this reduction.

(b) A feature of Tables 3C-D and Tables 4C-D is that the optimal reinsurance retentions are not very sensitive to changes in the time horizon for ruin. This suggests that if we wish to choose proportional reinsurance retentions which minimise the insurer's probability of ruin in either continuous or discrete time, subject to a minimum level for the insurer's expected net profit, it may be sufficient to calculate the optimal retentions for a short time horizon.

(c) A feature of Case Study 1 is that the optimal retentions in Tables $3 C(1,0.438 / 9$, $0.519 / 8)$, and $3 \mathrm{D},(1,0.456,0.493)$, are close to each other and not too far from those in Table 3B, $(1,0.396,0.581)$. Also, the corresponding probabilities of ruin in Tables 3B-D are all very close to each other. This suggests that, in this example, if we wish to choose retention levels which minimise a probability of ruin, in either continuous or discrete time, an approximation can be obtained by calculating retention levels using the minimum variance criterion. This could be a significant point since the computational effort required for the latter is considerably less than that required for the former.

(d) The comments in (c) above, all of which related to Case Study 1, do not apply to Case Study 2. For Case Study 2, the optimal retentions, and ruin probabilities, calculated using a minimum variance criterion, Table $4 \mathrm{~B}$, and a continuous time ruin 
criterion, Table $4 \mathrm{C}$, are very close to each other. Also, the optimal retentions in Table $4 \mathrm{C}$ give an expected net profit for the insurer of exactly 50 . However, the optimal retentions and ruin probabilities calculated using the discrete time ruin criterion, Table $4 \mathrm{D}$, are very different from those in Tables $4 \mathrm{~B}$ and $4 \mathrm{C}$. A noticeable feature of Table $4 \mathrm{D}$ is that the optimal retentions give expected net profits, $88.4 / 6$, well in excess of the constrained minimum value of 50 .

(e) A common feature of Tables 3A-D and 4A-D is that, for a given set of retentions and a given time horizon, the probaility of ruin in continuous time is a factor of almost 10 times greater than the probability of ruin in discrete time. To see why this is the case, consider Table 3B. The insurer's initial surplus is 20 and the expected surplus at the end of the first year is 70 . This indicates that if ruin occurs in continuous time, it is likely to occur soon after time 0 , so that there will be a large part of the year remaining in which the surplus can recover to a positive value. In fact, the probability of ruin in continuous time within the first half year is 0.0758 so that the probability of ruin in the following half year, having not been ruined in the first half year, is 0.0140 . In general we would expect the probabilities of ruin within a given time period (continuous) and at the end of the time period (discrete) to be much closer if either the insurer's initial surplus were larger and/or the expected net profit in the time period were smaller. Referring again to the example in Table 3B, the probability of ruin at the end of 0.1 years is 0.0166 . The important feature in this case is that the insurer's expected net profit in the time period is only 5.

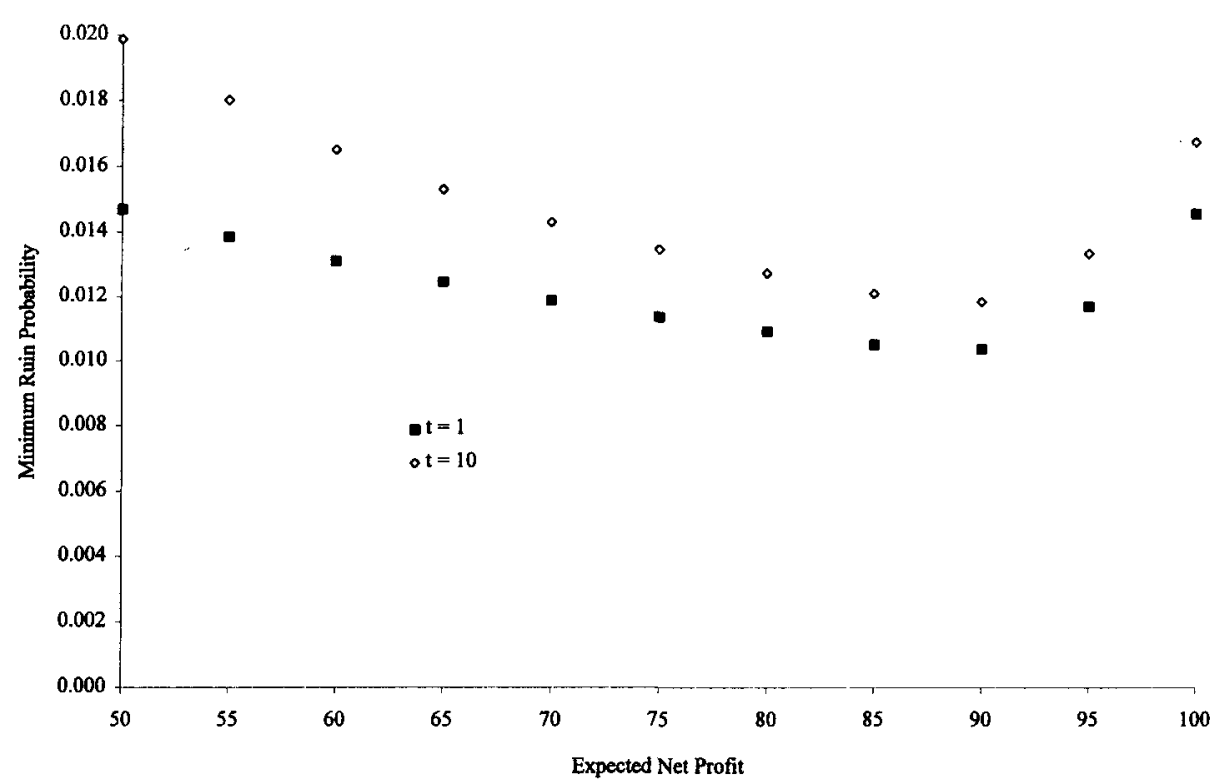

FIGURE 1: Proportional reinsurance, discrete time ruin, $U=35$, loadings are $10 \%, 40 \%$ and $80 \%$. 


\section{Further discussion of Case Study 2:}

Figure 1 shows minimum discrete time ruin probabilities as a function of the insurer's expected net profit for $t=1$ and $t=10$. This figure shows the advantage to the insurer of constraining the expected net profit to be at least 50. In particular, when $t=$ 10 we see that any expected net profit greater than 50 results in a lower probability of ruin than when the expected net profit equals 50 . Results showing the effect of different values for the initial surplus are shown in Tables $5 \mathrm{~A}, 5 \mathrm{~B}, 6 \mathrm{~A}$ and $6 \mathrm{~B}$, in all cases the reinsurance premium loadings are as in Case Study 2. Tables 5A and 6A show figures for an initial surplus of 20 and Tables $5 \mathrm{~B}$ and $6 \mathrm{~B}$ show figures for an initial surplus of 50. Tables $5 \mathrm{~A}$ and $5 \mathrm{~B}$ show for each of the five time horizons the optimal retention levels calculated using a continuous time ruin criterion, together with the resulting expected net profit for the insurer and the minimum value of the ruin probability. These values should be compared with those in Table 4C. Tables 6A and 6B show the optimal retention levels calculated using a discrete time ruin criterion. These values should be compared with those in Table 4D.

The optimal retentions in Table $5 \mathrm{~B}$ are very close to those in Table $4 \mathrm{C}$, indicating that increasing the insurer's initial surplus from 35 to 50 has had little effect in terms of optimal retention levels and the insurer's expected net profit. However, Table 5A displays different features. The optimal retention levels change as the time horizon increases, appearing to converge to $(1,0.827,0.256)$, and the insurer's expected net profit moves away from the constrained minimum value. Table $5 \mathrm{~A}$ indicates that the optimal retentions under a continuous time ruin criterion may depend on the time horizon and, by comparison with Tables $4 \mathrm{C}$ and $5 \mathrm{~B}$, on the insurer's initial surplus. Turning to Tables $6 \mathrm{~A}$ and $6 \mathrm{~B}$, we see that a change in initial surplus has only a small impact on optimal retention levels and the insurer's expected net profit.

TABLE 5A

MINIMUM PROBABILITY OF RUIN IN CONTINUOUS TIME, $U=20$

\begin{tabular}{cccc}
\hline \hline $\boldsymbol{t}$ & $\underline{a}$ & $\begin{array}{c}\text { Prob'y of ruin } \\
\text { (continuous) }\end{array}$ & $\begin{array}{c}\text { Expected } \\
\text { net profit }\end{array}$ \\
\hline 1 & $(1,0.753,0.231)$ & 0.1883 & 50.0 \\
2 & $(1,0.799,0.247)$ & 0.2025 & 56.8 \\
5 & $(1,0.827,0.256)$ & 0.2050 & 60.9 \\
10 & $(1,0.827,0.256)$ & 0.2050 & 60.9 \\
20 & $(1,0.827,0.256)$ & 0.2050 & 60.9 \\
\hline
\end{tabular}

TABLE 5B

MINIMUM PROBABILITY OF RUIN IN CONTINUOUS TIME, $U=50$

\begin{tabular}{cccc}
\hline $\boldsymbol{t}$ & $\underline{a}$ & $\begin{array}{c}\text { Prob'y of ruin } \\
\text { (continuous) }\end{array}$ & $\begin{array}{c}\text { Expected } \\
\text { net profit }\end{array}$ \\
\hline 1 & $(1,0.747,0.271)$ & 0.0288 & 50 \\
2 & $(1,0.747,0.271)$ & 0.0362 & 50 \\
5 & $(1,0.748,0.264)$ & 0.0387 & 50 \\
10 & $(1,0.748,0.264)$ & 0.0387 & 50 \\
20 & $(1,0.748,0.264)$ & 0.0387 & 50 \\
\hline
\end{tabular}


TABLE 6A

MINIMUM PROBABILITY OF RUIN IN DISCRETE TIME, $U=20$

\begin{tabular}{cccc}
\hline \hline $\boldsymbol{t}$ & $\underline{\boldsymbol{a}}$ & $\begin{array}{c}\text { Prob'y of ruin } \\
\text { (continuous) }\end{array}$ & $\begin{array}{c}\text { Expected } \\
\text { net profit }\end{array}$ \\
\hline 1 & $(1,1,0.460)$ & 0.0186 & 89.2 \\
2 & $(1,1,0.470)$ & 0.0205 & 89.4 \\
5 & $(1,1,0.470)$ & 0.0208 & 89.4 \\
10 & $(1,1,0.470)$ & 0.0208 & 89.4 \\
20 & $(1,1,0.470)$ & 0.0208 & 89.4 \\
\hline
\end{tabular}

TABLE 6B

MINIMUM PROBABILITY OF RUIN IN DISCRETE TIME, $U=50$

\begin{tabular}{cccc}
\hline \hline $\boldsymbol{t}$ & $\underline{\boldsymbol{a}}$ & $\begin{array}{c}\text { Prob'y of ruin } \\
\text { (continuous) }\end{array}$ & $\begin{array}{c}\text { Expected } \\
\text { net profit }\end{array}$ \\
\hline 1 & $(1,1,0.390)$ & 0.0055 & 87.8 \\
2 & $(1,1,0.400)$ & 0.0063 & 88.0 \\
5 & $(1,1,0.405)$ & 0.0065 & 88.1 \\
10 & $(1,0.405)$ & 0.0065 & 88.1 \\
20 & $(1,1,0.405)$ & 0.0065 & 88.1 \\
\hline
\end{tabular}

\section{EXCESS LOSS REINSURANCE}

Case Study 3: In this Case Study we investigate different optimal retention levels for excess loss reinsurance of the fire and windstorm sub-portfolios. For the reasons given in Section 2, we assume that the glass sub-portfolio is not reinsured under an excess loss treaty. The insurer's premium income is 600 , as in the previous two Case Studies, and the initial surplus is 35 . The reinsurance premium loading factors are $100 \%$ (fire) and $200 \%$ (windstorm). These factors are higher than those in the previous two Case Studies, a consequence of the fact that excess loss, by its very nature, should be more expensive than proportional reinsurance.

The probabilities of ruin, for continuous and discrete time, and for different time horizons, when there is no reinsurance are as in Table $4 \mathrm{~A}$. We will assume that the insurer wishes to find the optimal excess loss retentions subject to the constraint that the expected net profit is at least 50 . The minimum variance solution to this problem is $\underline{M}=(\infty, 9.66,19.32)$. The ruin probabilities with this set of retention levels are shown in Table 7B. Table 7C shows the optimal continuous time retentions and ruin probabilities for different time horizons, together with the discrete time ruin probabilities for these retentions and the insurer's expected net profit, which in every case is 50 . Table $7 \mathrm{D}$ shows the optimal discrete time retentions and ruin probabilities for different time horizons, together with the continuous time ruin probabilities for these retentions and the insurer's expected net profit. 
TABLE 7B

CAse STUdy 3 - Minimum VARIANCE

\begin{tabular}{ccccc}
\hline $\boldsymbol{t}$ & $\underline{\boldsymbol{M}}$ & $\begin{array}{c}\text { Prob'y of ruin } \\
\text { (continuous) }\end{array}$ & $\begin{array}{c}\text { Prob'y of ruin } \\
\text { (discrete) }\end{array}$ & $\begin{array}{c}\text { Expected } \\
\text { net profit }\end{array}$ \\
\hline 1 & $(\infty, 9.66,19.32)$ & 0.0420 & 0.0068 & 50 \\
2 & $(\infty, 9.66,19.32)$ & 0.0485 & 0.0083 & 50 \\
5 & $(\infty, 9.66,19.32)$ & 0.0499 & 0.0087 & 50 \\
10 & $(\infty, 9.66,19.32)$ & 0.0499 & 0.0087 & 50 \\
20 & $(\infty, 9.66,19.32)$ & 0.0499 & 0.0087 & 50 \\
\hline
\end{tabular}

TABLE 7C

CASE STUDY 3 - MINIMUM PROBABILITY OF RUIN IN CONTINUOUS TIME

\begin{tabular}{ccccc}
\hline $\boldsymbol{t}$ & $\underline{\boldsymbol{M}}$ & $\begin{array}{c}\text { Prob'y of ruin } \\
\text { (continuous) }\end{array}$ & $\begin{array}{c}\text { Prob'y of ruin } \\
\text { (discrete) }\end{array}$ & $\begin{array}{c}\text { Expected } \\
\text { net profit }\end{array}$ \\
\hline 1 & $(\infty, 10.43,17.39)$ & 0.0414 & 0.0066 & 50 \\
2 & $(\infty, 10.39,17,48)$ & 0.0479 & 0.0081 & 50 \\
5 & $(\infty, 10.38,17.50)$ & 0.0492 & 0.0085 & 50 \\
10 & $(\infty, 10.38,17.50)$ & 0.0493 & 0.0085 & 50 \\
20 & $(\infty, 10.38,17.50)$ & 0.0493 & 0.0085 & 50 \\
\hline
\end{tabular}

TABLE 7D

CASE STUDY 3 - MINIMUM PROBABILITY OF RUIN IN DISCRETE TIME

\begin{tabular}{ccccc}
\hline $\boldsymbol{t}$ & $\underline{M}$ & $\begin{array}{c}\text { Prob'y of ruin } \\
\text { (continuous) }\end{array}$ & $\begin{array}{c}\text { Prob'y of ruin } \\
\text { (discrete) }\end{array}$ & $\begin{array}{c}\text { Expected } \\
\text { net profit }\end{array}$ \\
\hline 1 & $(\infty, 11.52,19.09)$ & 0.0451 & 0.0066 & 54.7 \\
2 & $(\infty, 12.56,20.78)$ & 0.0543 & 0.0078 & 58.8 \\
5 & $(\infty, 12.91,21.37)$ & 0.0564 & 0.0081 & 60.1 \\
10 & $(\infty, 12.91,21.37)$ & 0.0564 & 0.0081 & 60.1 \\
20 & $(\infty, 12.91,21.37)$ & 0.0564 & 0.0081 & 60.1 \\
\hline
\end{tabular}

A comparison of Tables 7B-D shows that the ruin probabilities in these tables, either continuous or discrete time, do not change significantly from one table to the next. This indicates that for many practical purposes the probability of ruin, in either discrete or continuous time, can be assumed to attain its minimum value at the solution to the minimum variance problem. However, the extra computational effort required to compute the optimal retentions for discrete time ruin in Table 7D may be considered worthwhile since they result in an expected net profit for the insurer in excess of 60 , for $t \geq 5$, rather than 50 for the minimum variance optimal retentions.

Other features of Tables 7B-D are:

(a) the different time horizons in Tables $7 \mathrm{C}$ and $7 \mathrm{D}$ have little effect on the values of the optimal retention levels, and no effect for $t \geq 5$, and,

(b) optimal retentions for continuous time ruin, Table $7 \mathrm{C}$, are closer to the minimum variance solution than are the optimal retentions for discrete time ruin, Table 7D. In particular, the former give an expected net profit for the insurer of 50 , i.e. on the 
boundary of the constraint, as for the minimum variance solution, whereas the latter give an expected net profit away from the boundary.

Figure 2 shows the minimum discrete time ruin probabilities as a function of the insurer's expected net profit for $t=1$ and $t=10$. As in Figure 1 , we can again see the advantage of constraining the expected net profit to be at least 50 rather than exactly 50.

The effect of altering the insurer's initial surplus is shown in Table 8. This table shows for $U=20$ and $U=50$ the optimal retentions for both the continuous time and the discrete time ruin criteria, together with the minimum value for the probability of ruin and the resulting expected net profit for the insurer. In all cases the time horizon for ruin is 20 years.

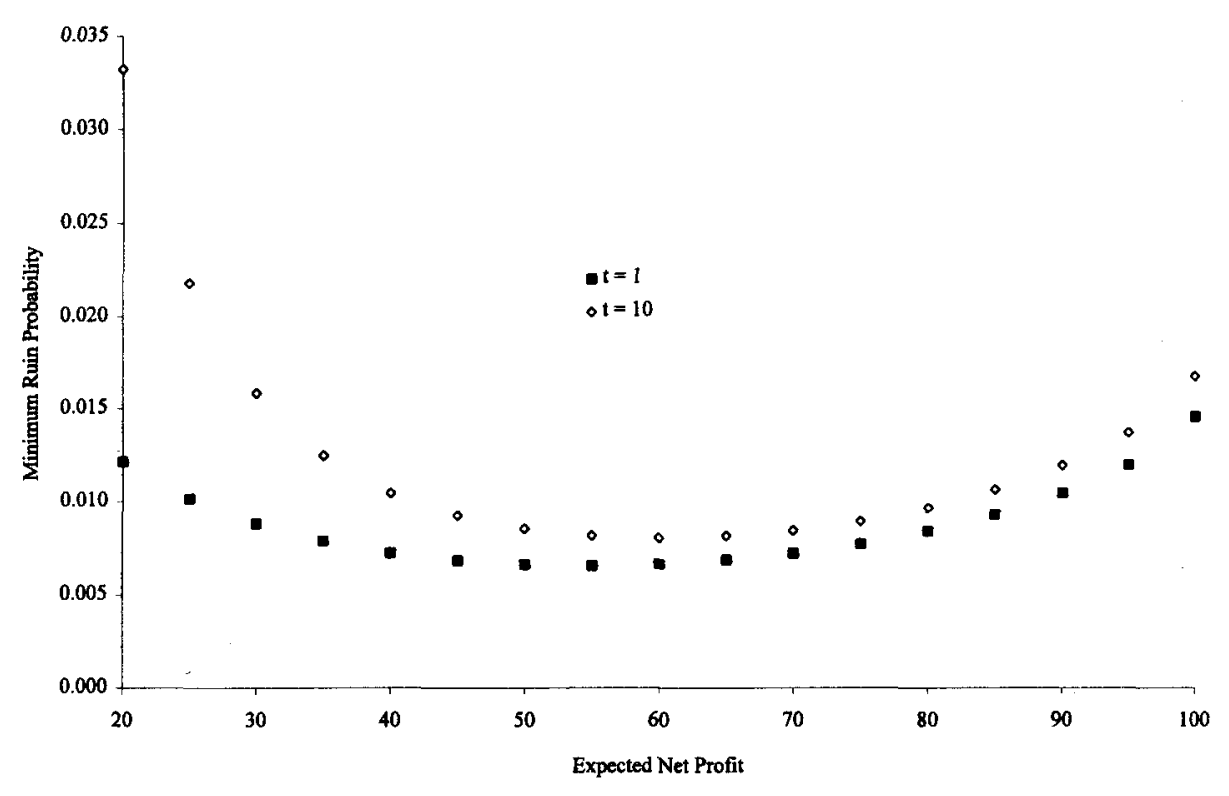

FIGURE 2: Excess loss reinsurance, discrete time ruin, $\mathrm{U}=35$, loadings are $100 \%$ and $200 \%$.

TABLE 8

CASE STUDY 3 - DIFFERENT VALUES FOR THE INITIAL SURPLUS: $t=20$

\begin{tabular}{ccccc}
\hline \hline $\boldsymbol{t}$ & $\begin{array}{c}\text { Continuous } \\
\text { discrete }\end{array}$ & $\underline{M}$ & Prob'y of ruin & $\begin{array}{c}\text { Expected } \\
\text { net profit }\end{array}$ \\
\hline 20 & Continuous & $(\infty, 10.08,18.22)$ & 0.1569 & 50 \\
50 & Continuous & $(\infty, 10.49,17.25)$ & 0.0155 & 50 \\
20 & Discrete & $(\infty, 16.18,27.00)$ & 0.0182 & 70.5 \\
50 & Discrete & $(\infty, 10.89,17.89)$ & 0.0031 & 51.8 \\
\hline
\end{tabular}


The important point revealed by Table 8 is that changing the insurer's initial surplus has little effect, in terms of the optimal retentions or the insurer's expected net profit, in the case of continuous time ruin but makes a considerable difference in the case of discrete time ruin.

\section{Conclusions}

Our purpose in this paper has been to investigate different criteria for determining the optimal relative retention limits for a non-life portfolio consisting of a number of independent sub-portfolios. For the reasons discussed in Examples 1, 2 and 3 in Section 4 , the minimum variance criterion could be regarded as a proxy for a probability of ruin criterion. The advantages of the minimum variance criterion are:

(a) it is possible to express the retention levels in closed form,

(b) the optimal retention levels depend only on the reinsurance premium loadings and, in the case of proportional reinsurance, on the first two moments of aggregate claims for the sub-portfolios, and,

(c) the optimal retention levels can be calculated very easily. In contrast, the optimal retention levels using a ruin probability criterion cannot be expressed in closed form and can be time consuming to compute, particularly for the Ionger time horizons.

Our method of investigation has been to carry out several "case studies" for a single portfolio. Using this method it can be difficult to draw any conclusions. Nevertheless, we consider that the numerical results in Sections 5 and 6 , and the other examples we have investigated in the course of this study, enable us to reach the following tentative answers, for both proportional and for excess loss reinsurance, to the questions posed in Section 1:

(1) The minimum variance criterion produces optimal relative retention levels close to those produced by the continuous time ruin criterion (see Tables $3 \mathrm{~B}$ and $3 \mathrm{C}$, Tables 4B, 4C, 5A and 5B and Tables 7B, 7C and 8 (Continuous)) but not necessarily similar to those produced by the discrete time ruin criterion (see Tables $4 \mathrm{~B}, 4 \mathrm{D}, 6 \mathrm{~A}$ and $6 \mathrm{~B}$ and Tables 7B, 7D and 8 (Discrete)). The three examples in Section 4 all indicated that optimality with respect to the minimum variance criterion might be approximately the same as optimality with respect to the probability of ruin in continuous time (Examples 1 and 3 ) and the probability of ruin in discrete time (Example 2). Specifically, we assumed in Examples 2 and 3 that the (retained) aggregate claim amount distribution could be reasonably approximated by a normal distribution, and hence is symmetric. However, with an expected net profit of at least 50 the coefficient of skewness of the retained aggregate claim amount distribution in Case Studies 1 and 2 turns out to be above 0.5 for all combinations of retention levels, and hence the distribution is not symmetric. For this reason it should not be surprising that optimality with respect to the minimum variance criterion can produce different results to optimality with respect to the probability of ruin in discrete time (Case Study 2). What may be considered surprising is the clo- 
seness of the results in all three case studies under the minimum variance criterion and the continuous time ruin criterion.

(2) As indicated in (1) above, the discrete time ruin criterion can produce very different optimal retentions from those produced by the continuous time ruin criterion. This should not be too surprising since these two probabilities are rather different both in nature and, in our examples, numerically. See comment (e) in Section 5. That these two probabilities behave differently has already been observed in a somewhat different setting. See Dickson and Waters (1996, Section 8 and 9).

(3) (i) In most cases we investigated, the optimal retention levels for continuous time ruin give an expected net profit for the insurer on the boundary of its constrained values (see Tables 3C, 4C, 5B, 7C and 8 (Continuous)). In one example this was not the case (see Table 5A). The exact reverse is true for the optimal retentions for discrete time ruin (see Table $3 \mathrm{D}$ for the former case and Tables $4 \mathrm{D}, 6 \mathrm{~A}, 6 \mathrm{~B}, 7 \mathrm{D}$ and 8 (Discrete) for the latter case).

(ii) A marked feature of all our calculations is that the time horizon for ruin, for one year and longer, has very little effect on the optimal retention levels in either continuous time or discrete time. In all cases the optimal retention levels are unchanged to three significant figures as the time horizon increases from five years to twenty years.

(iii)The insurer's initial surplus, which is not considered by the minimum variance criterion, can have a considerable effect on the optimal retention levels using a probability of ruin criterion (see Tables 7D and 8 (Discrete)).

\section{REFERENCES}

Bühlmann, H. (1970) Mathematical methods in risk theory. Spinger Verlag, New York.

DE FinetT, B. (1940) Il problema dei pieni. Giorn. Ist. Ital. Attuari 11, 1-88.

DICKSON, D.C.M. and WATERS, H.R. (1993) Gamma processes and finite time survival probabilities. ASTIN Bulletin 23, 259-272.

Dickson, D.C.M. and WATERS, H.R. (1996) Reinsurance and ruin. Insurance: Mathematics \& Economics $19,61-80$.

GrandelL, J. (1977) A class of approximations of ruin probabilities. Scandinavian Actuarial Journal Supplement, 37-52.

Ramlau-HANSEN, H. (1983) Fire claims for single-family houses. Presented at the XVII ASTIN Colloquium, Lindau.

RAMLAU-Hansen, H. (1986a) Statistical analysis of policy and claims data in non-life insurance: A solvency study. Part 1. Introduction to the study and analysis of glass claims. Working Paper No. 60, Laboratory of Actuarial Mathematics, University of Copenhagen.

RAMLAU-HANSEN, H. (1986b) Statistical analysis of policy and claims data in non-life insurance: A solvency study. Part 2. Analysis of fire claims. Working Paper No. 61, Laboratory of Actuarial Mathematics, University of Copenhagen.

Ramlad-Hansen, H. (1986c) Statistical analysis of policy and claims data in non-life insurance: A solvency study. Part 3. Analysis of windstorm claims. Working Paper No. 62, Laboratory of Actuarial Mathematics, University of Copenhagen.

RAMLAU-HANSEN, H. (1986d) Statistical analysis of policy and claims data in non-life insurance: A solvency study. Part 4. Analysis of windstorm claims. Working Paper No. 63, Laboratory of Actuarial Mathematics, University of Copenhagen. 
RamlaU-Hansen, H. (1988a) A solvency study in non-life insurance. Part 1. Analyses of fire, windstorm and glass claims. Scandinavian Actuarial Journal, 3-34.

RamLAU-HANSEN, H. (1988b) A solvency study in non-life insurance. Part 2. Solvency margin requirements. Scandinavian Actuarial Journal, 35-59.

DAVID C.M. DICKSON

Centre for Actuarial Studies

Faculty of Economics and Commerce

University of Melbourne

Victoria 3052

Australia

e-mail: ddickson@cupid.ecom.unimelb.edu.au

HOWARD R. WATERS

Department of Actuarial Mathematics and Statistics

Heriot-Watt University

Midlothian EH14 4AS

Great Britain

e-mail: H.R.Waters@ma.hw.ac.uk 